\title{
The Effective Application of Function and Excel Formula in University Computer Teaching
}

\author{
Xu Weihua
}

Linyi university, Linyi, Shandong, 276400

Keywords: Excel formula; Excel function; Computer teaching in colleges and universities

\begin{abstract}
As the past century is the electronic century generally, the early 21st century is the era of digital technology. In accordance with the new generation teaching process, we should pay more attention on it. In teaching, accordingly to some problems being aimed at, in the process of computer teaching in colleges and universities, the application of Excel becomes even more important because the majority of our current database is in this kind of composite form for management as a whole.

In the process of software office, Excel office system in modern office process reflects its strong adaptability and strong business capabilities. In the past, traditional statistical methods often takes the form of two or more persons, which struggles in corresponding statistics and accounting. And through Excel table management procedures, one or two people can complete the tedious work. The use of Excel in office can save a lot of manpower. Excel formula and function's roles in our current teaching of colleges and universities are analyzed in the following.
\end{abstract}

\section{EXCEL FORMULA AND FUNCTION}

In the use of Excel, they often involves the use of data, and these data's average value and variance of mixed operation in the process require repeated complex operation. In the past, we need to hire a number of professional knowledge talents for these tedious calculations, even so, there are corresponding errors, and Excel programming system can be simple in the process of statistics, which can be straightforward to calculate these answers. Its use, the application of formulas, is function and analysis. Excel program inputs a large amount of known formula, at the same time can also write your own formula, to carry out the corresponding operation. In university computer teaching, we can apply this very well, then the corresponding basic computer knowledge education to provide a basis for students to study in the future. Excel program has input more than 500 functions, mainly in financial, daily time, statistics and data analysis. But in the process of teaching in colleges and universities, often we only need to be familiar with more than 30 functions to finish our daily job. And teaching students how to use Excel can to a certain level help students learn the basis of digital statistics, etc.

\section{THE STATUS QUO OF COMPUTER TEACHING IN COLLEGES AND UNIVERSITIES}

\section{A. Effect of computer teaching}

Although computer teaching is still in its preliminary stage of development, but to a certain extent, it contributes to the promotion of students' autonomous learning ability which is mainly manifested in the following respects. First, subjective desire to enhance study. After several chapters computer study and practice, students master more learning skills. The increasing proficiency in computer operation steps up students' learning enthusiasm and generally high demands. Second, students' ability of autonomous exploration is greatly enhanced. Under the drive of interest, students gradually accelerate the accepting of knowledge, and the speed of grasp of new knowledge ability has a great improvement [1]. Third, the students' ability of flexible use of knowledge is enhanced. Influenced by the way of teaching, students in the stage of knowledge, showing the maximum live embraces of the concepts of learning, which applies existing knowledge to solve new problems, and effectively solve the problems in the study. For example, in the use of Excel function to solve transcripts of class arrangement, teacher will first teach students number 
from big to small arrangement method, and then ask them to find out the mean of the grades. By looking in automatic summation option in task bar, students then find the hidden average instruction, and successfully obtain the average value of the class. However, there are still lots of problems in computer teaching, which are worthy of education practitioners thinking.

\section{B. The main problems in computer teaching}

\section{Students overall quality difference is more noticeable}

Because of various factors influence such as education environment, family economic conditions and personal factors, students' computer knowledge level difference is big. How to make students improve the overall level of computer is the important problem needed to be solved in the research of computer teaching. Zero basis and a small amount of computer knowledge accounts for most of the students, most of these students lack the understanding about computers, and students' mastery of the knowledge in learning process is slower, which may cause students' mental pressure. Individual students may also appear disgusting and resistant emotion, which brings great challenge to teacher's teaching work[2].

\section{Student active learning consciousness is low}

Other subjects' study pressure directly influences the autonomy of learning computer course. The influence of traditional learning ideas and teaching methods make students more in a passive position, and lack of consciousness of active learning. Even if the student has strong curiosity and the desire of knowledge to the unknown and knowledge, due to the lack of correct method of study, his enthusiasm will be affected by frustration in different degree. Old knowledge mastering in computer learning is not in time, and the new knowledge is followed, which causes problems piled up and reduces students' thinking space and time. Students' autonomous learning consciousness is an important method to master computer knowledge. To achieve good teaching effect, we must exert students' subjective reason, arouse their autonomous enthusiasm of learning, and improve the ability of autonomous learning.

\section{COMPUTER CLASSROOM TEACHING PRACTICE}

In practice teaching, we aimed at the application of Excel, and how to teach the students the in understanding this system, which requires some simple teaching.

\section{A. Formula teaching application}

First of all, Excel formula in the process of writing begins with "=", and in the process of teaching, it needs the teacher to repeat the performance to the students. In the input of the cell, if directly input "2/10", then the cell will appear directly February $10 \mathrm{form}$, and if the input is "= 2/10", then there is 0.2. The input contraction is shown below.

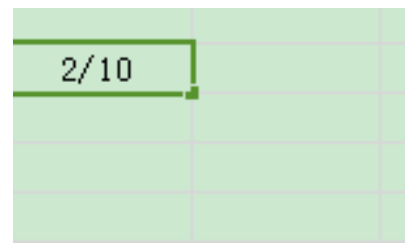

Figure 1

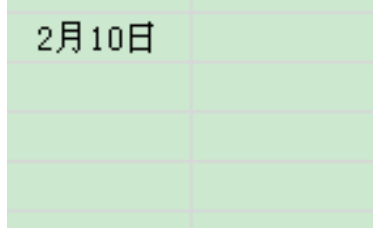

Figure 2

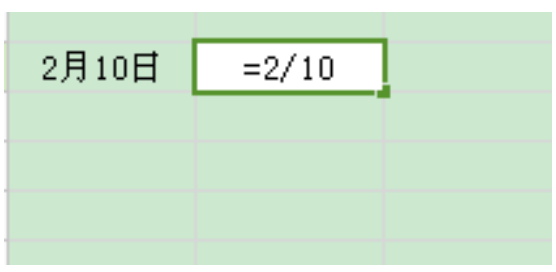

Figure 3

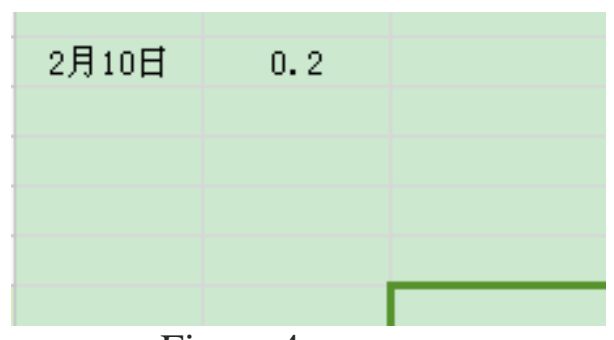

Figure 4

This means that, in Excel form input process, there are a lot of attention to be paid to the elements. These are all we should pay attention to in the teaching. Because form entry method will 
give the corresponding formula according to its corresponding input form, so in the application, it requires special attention.

Secondly, there are problems need to pay attention to in reference cell. Because reference formulas will involve in a column or a row of cells, in the process of calculation, if any special case need to note, or a wave data, then there is need for the corresponding transfer. In F3 for example, when we input "= b3 + c3 + d3 + e3", b3 behind the equals sign is introduced data, and after the input, F3 data will automatically turn into the summary of B3, C3, D3, and E3. The calculation is in the following Figure and Figure 6.

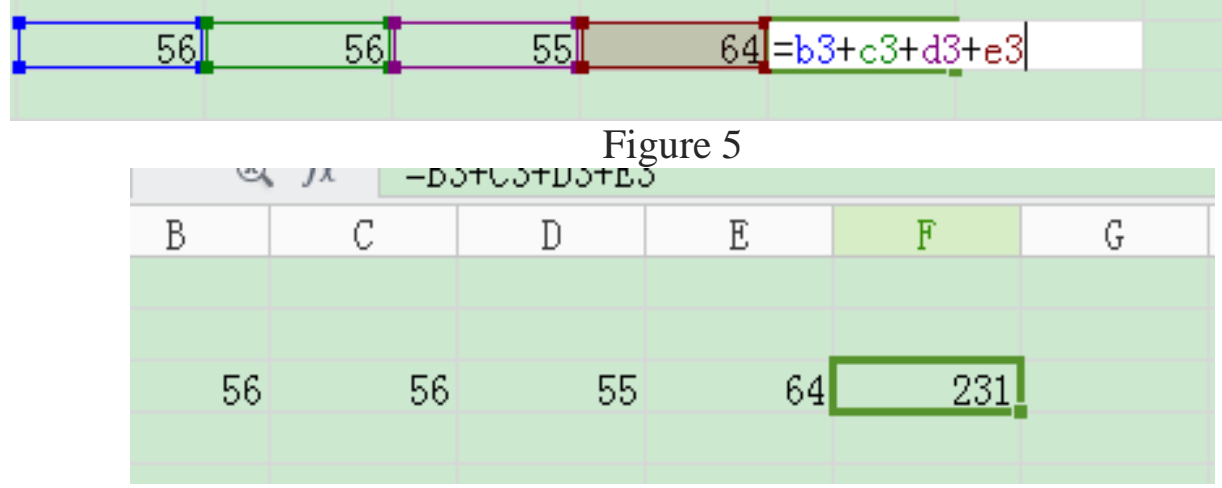

Figure 6.

Finally, in these simple formula calculation, we should also make use of the corresponding cell based on formula constants. Because the constants can cause some changes of the overall formula in the process of calculation. Such as in college entrance examination, English listening is not in the total score, and listening test accounts for 30 points. In order to guarantee the score is not affected, the written test is carried out in written part * $125 \%$ computing system. In statistics calculation, we have some trouble. If every student must carry on the computation, there are some troubles. We also can complete the data statistics through formula calculation. In the process of writing, we can write "= written $* 1.25+\ldots "$ computation formula to directly count all the grades of the designated position.

\section{B. Function application}

In computer application teaching process, because it involves a lot of concept problems, in teaching, we need to analyze function problems. Functions in computer Excel program mainly are the following four: SUM, AVERAGE, MAX and MINA. In teaching, we also should let students correctly understand that these functions are meaningful. It can give students some direct idea, and then skillfully master it.

In function application teaching, we can first build a new Excel file, and then according to student performance table, input the following table. Then educational sum, average, and the lowest scores, grade point average and class statistics are according to class lowest score statistics. One of the input is in the above formula, "= sum (- : -)", and use different functions for different values corresponding data entry. It can effectively find out in the corresponding statistical data needed for now. In the entry process, its style is as in Chart 1. 


\begin{tabular}{|c|c|c|c|c|c|c|c|}
\hline & $\mathrm{A}$ & $\mathrm{B}$ & $\mathrm{C}$ & $\mathrm{D}$ & $\mathrm{E}$ & $\mathrm{F}$ & $\mathrm{G}$ \\
\hline 1 & 姓名 & 语文 & 数学 & 英语 & 总分 & 平均分 & 名次 \\
\hline 2 & 陈小丽 & 78 & 89 & 91 & $=$ sum $\cdots$ & $=$ average $\cdots$ & $=$ rank $\cdots$ \\
\hline 3 & 郑春梅 & 43 & 52 & 47 & & & \\
\hline 4 & 喻进隆 & 76 & 84 & 63 & & & \\
\hline$\cdots$ & $\cdots \cdots$ & $\cdots \cdots$ & $\cdots \cdots$ & $\cdots \cdots$ & $\cdots \cdots$ & $\cdots \cdots$ & $\cdots \cdots$ \\
\hline 51 & 夏志雄 & 86 & 77 & 79 & & & \\
\hline 52 & 单科平均分 & $=$ average $\cdots$ & & & & & \\
\hline 53 & 单科及格率 & $=$ countif $\cdots$ & & & & & \\
\hline 54 & 单科不及格率 & $=$ countif $\cdots$ & & & & & \\
\hline 55 & 及格人数 & $=$ countif $\cdots$ & & & & & \\
\hline 56 & 不及格人数 & $=$ countif $\cdots$ & & & & & \\
\hline 57 & 参加考试人数 & $=$ count $\cdots$ & & & & & \\
\hline
\end{tabular}

Chart 1

Function can effectively locate the value we need, for example in semester numerical simulation, to be a baseline comparison with other schools, you need to take out the grade point average, and high head, so it requires statistics in $\mathrm{x}$ band. While the process of statistics in the past needs a large number of statistical reports, and then verify one by one, but in the application of Excel program, we can effectively finish the job quickly.

Function teaching process and the formula are similar, but function is more targeted and formula is just some simple applications, and they are mainly equivalence relations.

\section{MEASURES ACCORDING TO STUDENTS’ APTITUDE IN COMPUTER TEACHING IN COLLEGES AND UNIVERSITIES}

For a long time, we are all learning English with mouth closed, and in the same way, hands cut in computer teaching. That may seem a little exaggerated, but for a long time, this is what we did for teaching. In the $1990 \mathrm{~s}$, every student needs to buy a Wubi root table, and then resite before graduation without a touch of a keyboard before graduation. The dorsal root or theory is like passing a wooden bridge with your eyes closed. In the rapid development of modern teaching, we can use the advantageous resources to let students safely study in machine learning. And skilled mastering of Excel has a very broad education significance in facing changes in our teaching and heavy teaching tasks. Educate students how to pay attention to filling out the form and entry is also a significant change in basic education. So in a long period of time following, we need to adjust according to students' aptitude, so we can try our best to the development of students in learning process, which can effectively learn things they should learn at this stage, and in the application of these new knowledge at the same time, they also can solve their substantive issues encountered in the study.

\section{A. Improve teaching methods and enhance the interest of learning}

Interest is the foundation of students' learning progress, and teachers should use innovative teaching methods, understand students' learning characteristics and state of mind, and develop a more suitable teaching plan for students. For example, in daily learning, organize computer skills competition to encourage students' participation, Driven by competition, arouse their motivation and self-esteem, and let the students develop students' thinking and take the initiative to seek more solutions to the problem in the process of participating and preparation. Determine the student's main body status, and make teaching focus on strengthening students' thinking ability, and attach great importance to problem solution teaching work [3]. Rapid progress in computer technology asks for students to maintain long-term professional advantage, enhance their independent ability to deal with problems, adhere to the unity of theory and practice teaching methods. In Chapter Word illustration, for example, the teacher first gives a brief introduction to the teaching material, and then, guides students to operate Word, explains each option function in the menu bar, and makes the students feel Word formation process. Finally, students are encouraged to freely play and create a 
text to work independently, so as to achieve the goal of exercise students' autonomous learning ability.

\section{B. Make reasonable teaching tasks according to their aptitude}

Computer teaching materials are professional knowledge with blurred boundary and are difficult to understand. Teachers' understanding and induction to the outline substance, appropriate increase or decrease of the teaching material are better. Different students have different hobbies; others like programming knowledge; some like writing; some like hardware, and teachers should according to the students' interests, give the right knowledge guide to make it get into full play. In addition, in view of students' personality, give guidance respectively. Teachers should strengthen the communication with introverted students, and let them feel care of teachers with stronger teaching interaction to build a good teaching atmosphere. For the lower level students' learning, give patient explanation and guidance to enhance their confidence.

\section{CONCLUSION}

In colleges and universities teaching, teachers should follow the changes of The Times and study computer application ability. Thus in the process of education, promote students' study information technology. Excel is the most basic office software, and its formula and statistical aspects of function are also enough for the demand of daily office. And now in computer teaching, we should also pay attention to students' actual operation ability. It has wide range of effects for the ability of whole skill learning, and in the process of their own progress, we also need some fundamental understanding for these new ideas.

\section{REFERENCES}

[1] Lei Qiang. Use opportunely Excel function [J]. Journal of Xianning College, 2004, 24 (3) : 154-156.

[2] Wu Bin. Analyze the use of Excel formula and function in college computer teaching[J]. China's New Communications, 2015, (3) : 91-91.

[3] Xie Qingsheng. Introduction to effective implementation of university computer teaching method [J]. China's School Education (o 'clock), 2011, (7) : 39.

[4] Xu Sufang. How to cultivate students' innovative thinking in computer teaching [J]. Love Tomorrow, 2014, (9) : 133-133.

[5] Wang Yufen. The application of interactive teaching mode in college computer teaching [J]. Chinese Science and Education Innovation Tribune, 2014, (9) : 45.

[6] Wang Chunhong. The effectiveness of computer teaching in colleges and universities [J]. Urban Family Education: First Half of the Month, 2012, (3) : 26-26. 